\title{
FRANÇOIS DESPLANQUES, Mohammed Dib Essentiel-lement poète
}

\section{Emanuela Cacchioli}

\section{(2) OpenEdition}

\section{Journals}

\section{Edizione digitale}

URL: https://journals.openedition.org/studifrancesi/12231

DOI: 10.4000/studifrancesi. 12231

ISSN: 2421-5856

\section{Editore}

Rosenberg \& Sellier

\section{Edizione cartacea}

Data di pubblicazione: 1 avril 2018

Paginazione: 175-176

ISSN: 0039-2944

\section{Notizia bibliografica digitale}

Emanuela Cacchioli, «françoıs desplanaues, Mohammed Dib Essentiel-lement poète», Studi Francesi [Online], 184 (LXII | I) | 2018, online dal 04 juillet 2018, consultato il 17 novembre 2021. URL: http:// journals.openedition.org/studifrancesi/12231 ; DOI: https://doi.org/10.4000/studifrancesi.12231

Questo documento è stato generato automaticamente il 17 novembre 2021.

\section{(a) $\odot \Theta$}

Studi Francesi è distribuita con Licenza Creative Commons Attribuzione - Non commerciale - Non opere derivate 4.0 Internazionale. 


\title{
FRANÇOIS DESPLANQUES, Mohammed Dib Essentiel-lement poète
}

\author{
Emanuela Cacchioli
}

\section{NOTIZIA}

FRANÇOIS DESPLANQUES, Mohammed Dib Essentiel-lement poète, Paris, L'Harmattan, 2016, 190 pp.

1 Lo scrittore algerino Mohammed Dib è conosciuto soprattutto per i suoi romanzi, sebbene la sua produzione sia molto variegata e comprenda pièce teatrali, racconti per l'infanzia, novelle e raccolte poetiche. È proprio quest'ultimo aspetto ad essere studiato nella monografia di François Desplanques. Il critico, specialista di Dib, analizza le nove raccolte di poesie pubblicate dall'autore algerino, ad ognuna delle quali dedica un capitolo in cui si individuano le linee tematiche essenziali, le caratteristiche della scrittura poetica, gli aspetti lessicali, sintattici e metrici dei componimenti. Dal momento che i volumi sono presentati in ordine cronologico, è possibile rintracciare anche l'evoluzione del pensiero e la modalità di approccio alla poesia da parte dello stesso Dib. Riscopriamo, quindi, Ombre gardienne, opera in cui il poeta parla dell'Algeria e del suo esilio a Parigi e Formulaires, che introduce il tema del desiderio, poi ripreso e approfondito in Omneros e Feu, beau feu. La fluidità dell'acqua e la sensualità del corpo femminile sono i temi affrontati in $O$ Vive. L'Aube Ismael è invece una raccolta che parla dell'esilio, ma anche della bellezza inquietante del deserto. Il percorso prosegue con il richiamo all'erranza, alla solitudine, al coraggio e alla morte in L'Enfant-Jazz e in Le Cour insulaire. Con L. A. Trip, il tema dell'emigrazione viene contestualizzato nel continente americano e nello specifico nella dimensione urbana soffocante della città di Los Angeles.

2 Attraverso l'analisi dei componimenti, François Desplanques mette in luce il ruolo fondamentale che il cosmo ha per Mohammed Dib: il fuoco, l'acqua, la terra e l'aria costituiscono il serbatoio principale da cui attingere le immagini reali e metaforiche 
sulle quali sono costruite le poesie. La natura per Dib racchiude una miriade di segni e di presagi che possono essere svelati attraverso una lettura attenta che sappia interpretare il linguaggio simbolico e spesso ellittico del poeta. Tali caratteristiche rivelano l'altro filone di riflessione che permea tutta la produzione poetica di Dib: l'essere umano e la sua complessità interiore. L'uomo e la donna costituiscono l'unità e la molteplicità: tra di loro si crea attrazione, nasce il desiderio e con esso la forza, la bellezza, ma anche il lato oscuro del sentimento. Quest'ultimo può essere all'origine di una carica positiva, ma può generare anche inquietudine, attesa, a volte persino una violenza latente. Il presagio della morte è un'ossessione che ritorna in molti testi e che diventa sempre più concreto nelle ultime poesie, scritte in età più avanzata.

3 L'erranza va, dunque, intesa come spostamento nello spazio geo-politico (Algeria, Francia, Stati Uniti), nella natura (dal deserto alle grandi pianure), all'interno della dimensione urbana (Parigi, Los Angeles), nell'interiorità umana, nei suoi misteri e nel desiderio di discrezione che mantengono la psiche impenetrabile, ma anche nel patrimonio culturale e letterario internazionale (sono numerosi i riferimenti ad Aragon, Baudelaire, ai miti dell'antica Grecia e alla Bibbia, solo per citarne alcuni).

Il volume è uno strumento utile per un primo approccio alla poesia densa e complessa di Mohammed Dib. Oltre a una guida per il lettore che si lascia condurre nell'universo poetico dello scrittore algerino e un tentativo per far conoscere meglio la sua poesia, lo studio di Desplanques vuole essere anche un'esortazione per la critica a rileggere $\mathrm{i}$ romanzi di Dib a partire dalla prospettiva poetica e dagli snodi tematici individuati in questo volume. 